\title{
SCIENCE AND EDUCATION IN THE CONDITIONS OF FORMATION OF THE GLOBAL WORLD
}

\begin{abstract}
World science and education at the beginning of the third Millennium are in a pronounced bifurcation stage - at a fundamental turning point in its development. A global direction of research has already been formed, including globalistics, global scientific disciplines, globalisation studies, global evolutionism and a number of other areas of scientific research. Although this global cluster of scientific knowledge is most intensively developed only in the second half of the last century, its origins are found in the works of V. I. Vernadsky at the beginning of the same century. The global cluster of scientific knowledge is associated with the globalisation of education and the formation of global education. It is noted that the globalisation of education is focused mainly on the formal and organisational methods of integration of different systems and forms of education; the most important directions of this process are highlighted. And global education is characterised by qualitative and meaningful transformations of the educational process, the subject field of which is "filled" with universal-integrative knowledge obtained in the course of global studies. It is assumed that with the globalisation of science and education begins a new global revolution in the scientific and educational space.
\end{abstract}

Keywords: globalistics, globalisation of education, global studies, global education, global revolution in science.

Introduction

The peculiarity of the modern stage of development of science and education in a globalizing world is that their transformation is increasingly not so much evolutionary as revolutionary. The author will illustrate this position on the example of the development of science and education in their global dimension, and the choice of this dimension (direction) is connected with new horizons of transformations of scientific and educational space, which were simply not noticed earlier. The global direction of science and education largely concentrates and in an integral form expresses the ongoing social transforma- tions in these areas and allows us to see the new trends that characterise the emerging global world.

Stages of development of science, when there is a qualitative transformation of the fundamental foundations of science, created fundamentally new scientific theories, approaches, methods, methods of scientific research, are considered scientific revolutions. The most largescale transformations in the Russian literature are called "global scientific revolutions", they are following each other - the formation of classical natural science, the formation of the disciplinary organisation of science, the emergence of nonclassical natural science and, finally, post-non- 
classical science.

Here, the meaning of the term "global" (revolution) suggests that a revolutionary revolution in the foundations of science will extend, in principle, to the whole of science in general, regardless of what object is being studied. "global" in this case acts in the sense of general scientific and is presented as a process unfolding in time and exciting an increasing number of areas of scientific research ("potential globality"). But the new global revolution in science (and, accordingly, in education), which is considered here, has a different meaning when the "global" in science appears as global processes and systems, without claiming as the mentioned transformations to general science.

\section{Global Transformations of Science as a New Global Revolution}

It hardly makes sense to reduce the global direction in science only to the emergence of globalistics, which was often done until recently. Global research at the present stage began to form as a global cluster of scientific knowledge, including globalistics as the "core" of these studies, individual global disciplines, global evolutionism. The results of research of any scientific problem "in the conditions of globalisation" (or the influence of other global phenomena) are added to the global cluster of scientific knowledge from time to time, contributing to the formation of its "global status" and testifying to the further deployment of a new global revolution in science (Ursul, 2019 ${ }^{\mathrm{a}}$ ).

Since the cluster of global knowledge is considered, it makes sense to identify the origin of each of the components of this cluster, considering them as an evolutionary process of globalisation of scientific research. At first, global knowledge appeared in syncretic (latent-undivided) form in V. I. Vernadsky in 1902-1903 and especially in the first half of the XX century. Not only in Russia but also in world science as a whole V. I. Vernadsky laid the "first bricks" in the study of global processes (Ursul, 2018 ).

It is widely believed that global areas of scientific knowledge began to be actively developed only with the advent of globalistics in the second half of the 60 s of the last century. As an example, we can point to the global environment, exploring the totality of all living organisms of the planet in interaction with their environment, which began to form since the late 40 -ies of the last century. And before the advent of globalistics began to emerge some global disciplines (inertia disciplinary development of science), among which we have identified the global environment in its basic biological version.

Globalistics acts as the main direction and stage of the formation of global studies. Globalistics began to form when such global phenomena (processes and systems) as global problems threatening the further existence of mankind began to be studied. At the same time, a global approach to sociology appeared, most likely under the influence of the global worldview and the beginning of the study of global problems. Also in the early 70 s of the last century began to form a global (universal) evolutionism mainly under the influence of understanding the problems of space exploration.

Globalistics gives rise to new interdisciplinary forms of scientific knowledge, interacting with various scientific disciplines that reveal the willingness and ability to evolve in a global direction. Thus, already existing scientific disciplines are external sources for "global synthesis" and are interdisciplinary in nature. However, this interdisciplinary interaction is not the only source 
of the emergence of various integrative areas of globalistics.

Globalistics focuses on global processes and systems as objects of research. The primary for it is the object of study (global phenomena) as a broader concept, and the secondary is the subject of study, in which a certain property or characteristic of the object is allocated, borrowed by globalistics from a particular scientific discipline.

Emerging global disciplines continue to study the same objects as before, expanding their subject area now on a global scale and dimension. The formation of new interdisciplinary sections of globalistics is also associated with globalisation studies, which study different directions of globalisation. They are the internal mechanism for the formation of integrative sections of globalistics, which have not only an interdisciplinary nature. Thus, in the course of globalisation of science appeared global studies, which include globalistics, and within it began to develop globalisation research (3G).

One of the sources of global phenomena is local and regional processes. These processes have a substantial and qualitative sign of globality (but not yet territorial). They then expand in spatial-geographical scale and can become common planetary processes, summing up the consequences and features of the previous development of civilisation. Thus, the formation of "potential globality" occurs during the transformation of local processes into regional, and later into the corresponding g-local and global phenomena (Ursul, 2019 ).

Something similar takes place at the theoretical and cognitive level in the process of formation of global studies. The new global knowledge that is generated comes when a research objective is set for a scientific problem, for example, "in the context of globalisation" or "glob- al risks", and then this knowledge is included in a specific area of research, which thus begins to globalise.

There are areas of scientific knowledge that have previously investigated certain global processes that clearly did not use (but rather simply did not declare) a global approach. The most characteristic example of this kind of knowledge can be anthropology, which studied such global processes as global human settlement, the use of fire, the neolithic revolution, etc.

Since a certain time, the deployment of globalisation took place in two forms - spontaneous and directed by one or another state (in the unipolar world, this role was mainly performed by the United States). A slight decline in the pace of this "directed" form of globalisation, especially since the Trump presidency, does not mean that globalisation as a whole has ended, it continues and this process can hardly be stopped, although it takes new forms, including through the beginning of the transition to sustainable development.

One of the important trends in the globalisation of science is that globalistics, as the most dynamic component of global research, has already shown not only disciplinary but also interdisciplinary and integrative intentions. Thus, there is a transformation of globalistics into a global cognitive system, involving a significant part of the existing scientific knowledge in the global sphere of scientific research, which will increasingly focus on a new form and strategy of the evolution of civilisation - global sustainable development (SD).

A new global revolution in science will not be able to "capture" the entire scientific space, because there are and there will be other, "nonglobal" areas of scientific research, for example, regional or local (if allocated by spatial parame- 
ter). But on other grounds, you can find studies that, in principle, do not have a "global status". This suggests that this "global revolution" will not cover the whole of science as a whole, but only part of it, albeit very significant (but will have an impact on another part).

If earlier social transformations led to the fact that the "global scientific revolutions" were built one after another on a temporal trajectory, now the "new global revolution in science" is combined and interacts with a number of other scientific and revolutionary transformations - in the field of information, ecology, space and astronomical research, NBICS technologies, etc. Global studies are included in the ongoing "multi-revolutionary explosion" in modern science when almost in the same historical period there is not one - another "global scientific revolution", but a whole complex of cardinal, including general scientific, transformations in science (Ursul, $2018^{\mathrm{b}}$ ).

\section{The emergence of New Global}

Forms of Education

Modern education is not sufficiently focused on the future, on the creation of its systemic model that will ensure the survival of the human race in the future, especially in the distant future. The system of knowledge and values that operates in education has not yet been adapted to a future that will become a global and secure world. Nevertheless, there are already those trends in the formation of education in the globalizing world, which, as well as the formation of global science, unfold in the directions that follow both from the past of this type of activity, and the influence of the current social transformations (Ursul, 2019 ${ }^{\mathrm{C}}$ ).

First of all, we are talking about the globali- sation of education as a trend of universalisation of forms and structures (institutions), as well as the relationship of all components of world education in a holistic system. We do not call this system global education, because this term has a different meaning. Globalisation of education gives integrity to the contours (forms) of education, manifested in various globalisation processes in education, but does not focus on its content. Therefore, the formed integrity is largely formal and organisational in nature, gives education a "global form", which will be filled with the subject matter of a global nature, resulting in the emergence and development of global education.

This direction of globalisation of education is adjoined and strongly influenced by the form of globalisation of education, which is associated with its Informatisation, the use of information and communication technologies and the formation of "smart education". The future global world in a certain context will be an information society, which becomes at the same time a society of knowledge and a society of education, as it implies accelerated advanced development of science and education and other spheres of spiritual culture. Smart education, which makes extensive use of new information technologies, should become a priority mechanism for the development of a global information society with sustainable development (SD).

So far it is a small part of the world education, which began to develop only about half a century ago, a few years after the first forms of global knowledge, gradually including its new types and sections. Although the territory of global education will only grow, however, it does not displace other components of the world educational process. It is through this global information process that global knowledge from the above-mentioned global cluster of scientific 
knowledge increasingly fills education with global content, as a result of which it in some part becomes a global education. So far, it will remain only a part of the world's education, but its role in it will increase as the global world develops.

Education at the present stage, and even more so in the future global world, can no longer be limited to its inertial and translational function (transfer of the past to the present) because changes are often faster than the assimilation of knowledge by living generations. Scientific knowledge and other forms of culture that function in education, at the time of their transfer to education, are obsolete and of little use to combat crisis phenomena and protect against increasing threats and dangers. The emerging global world "requires" innovative global changes in education, which are largely concentrated and expressed in the model of education for sustainable development.

This form of education becomes not only a prerequisite for achieving sustainable development but also its priority means. The transition to global sustainability actually begins with the establishment of education for sustainable development, which has become one of the key tools for achieving the Millennium Development Goals, and those new 17 global Sustainable Development Goals (SDGs) that were adopted at the Summit on sustainable development, which adopted the Agenda for sustainable development until 2030. Thus, education for sustainable development (as a global process) will have to be ahead of the emergence of a sustainable future in its "full format".

This temporal feature of education for sustainable development was realised not only as a further greening of education but also as its futurisation, i.e. shift of emphasis on the study and modelling of the future (Ilyin \& Ursul, 2016) Leading mechanism anticipatory education consists of inclusion in education the problems of the future and much more fast (compared to other types of human material activities) development.

So far, the environmental vision of this form and direction of education prevails, so the task is to create an expanded general and systemic concept of education for sustainable development and identify its optimal ways and forms of development. It is obvious that education, which has become an attribute of human existence and development, should be reoriented to new universal goals (primarily the SDGs) and the fundamental values of the Third Millennium, corresponding to the new civilisational paradigm. Education should not only transmit relevant information from the past to the present but also create the desired image of the future, the future that is necessary for humanity. And this social reorientation changes the meaning of education, its role in the life of people.

Education as one of the most important social processes in its modern development should "foresee" and meet the needs of future generations of people who have not yet appeared and do not participate in the decision-making of their ancestors (who should make decisions for them). The responsibility for the future of mankind now lies with the present generations and the fate of our descendants depends on their decisions.

Future generations fall out of the understanding of education as a process of assimilation by the person of systematised knowledge, skills, abilities, experience, culture, past generations, and their transmission to the present generations, the "fall" (They do not exist and therefore do not take decisions.). Therefore, according to the principle of temporal integrity, in the educational 
process should be linked all three types of generations, leaving, now active and future, including not yet appeared. SD focuses on the connection of past and current generations with the future, and this requires a different interpretation of education, which could realise its new "saving" function for the whole civilisation.

However, it has become clear that humanity is not yet ready to accept and implement the sustainable development strategy as it currently exists at the conceptual and strategic level. It is important to significantly expand the subject field of scientific research on the problem of achieving global sustainability, to make the concept of SD as a global development more systemically holistic and thus - adequate and effective for the practical implementation and deployment of this global process.

The system of the interrelation of ecology, economy and social sphere (triad), in any case, in its modern representation for the increase of efficiency of future effective transition to SD it is necessary to expand essentially. It is advisable to turn the "space of movement towards global sustainability" into a kind of expanding n-dimensional phase space, where other dimensions will appear, from which it will be necessary to allocate priority areas and spheres of social activity, on which efforts and funds will be primarily focused. A new stage of world development will be associated with the formation of a new and more adequate concept of civilisational development, in which science and education will play a key role.

In principle, the future concept of education for sustainable development (ESD) will include as a priority those models of education that in their subject area are close to the problems of the new socio-natural model of evolution. The expected transformation of modern education will be associated primarily with the implementation of the already developed recommendations of the recent UN and UNESCO forums to achieve global sustainability, the further expansion of this concept beyond the predominantly "ecological" and even "triad" format, as well as with the development of goals, criteria and indicators of education for sustainable development.

Even though the environmental component (and the corresponding model) of education currently prevails in the form of education, which most teachers consider education for sustainable development, yet it is only the beginning of the formation of a new system-integral model of this form of education. SD ideas will be more or less embedded in existing disciplines, and not only from an environmental perspective because in principle ESD has a general scientific and interdisciplinary nature in both scientific and educational dimensions. But we mean not only interand multidisciplinary expansion of this type of education but also the addition and systematic integration of new models of education that contribute to the survival of civilisation through the achievement of global sustainability. Becoming temporal-holistic and universal-global, the formation of a future global world will transmit to present and future generations information and culture-oriented to overcoming global crises and cataclysms, to the survival of mankind and the indefinite long and safe evolution.

Education, conceived as a continuous innovation process, will not only have to be modernised, but also to a significant extent to be futurised, becoming more and more advanced education, not lagging behind modern life, and effectively paving the way to our common globally sustainable world. Advanced education in a sense, too, is a "remote" education, but not only in spatial coordinates but also in the time dimen 
sion, continuing the vector of futurisation.

The inclusion of the advance function, along with the transfer of knowledge, changes the very understanding, and hence the definition of "education". Education from this point of view is not only the translation of knowledge and culture from past generations to present and future but also the advanced preparation of a person for preventive effective actions on the transition to the strategy of sustainable development, the "ultimate" goal of which is the formation of the sphere of reason, ensuring the survival of civilisation and its further co-evolution with the remaining biosphere.

I believe that the model of education for sustainable development can be taken as a basis for creating a future holistic model of education in the global world. The basis of this statement is due to the fact that the future model of civilisation is sustainable development. Therefore, the model of anticipatory education, the vision of education based on the concept of "security through sustainable development", global education, smart education, and other models of education (for example, the model of space education based on the latest astronomy and astronautics), etc. will be added to the most developed environmental component of ESD.

\section{Conclusion}

Thus, from the second half of the past and the beginning of the present centuries, revolutionary transformations in science and education began to take the form of a nonlinear multirevolutionary explosion, capturing an increasingly significant part of the scientific and educational process and space. Its essence lies in the appearance of almost in the same historical period not one of the next global or complex revolution in education and science, but their whole cluster, which creates the scientific and educational basis for the formation of the future sphere of mind the noosphere, which acquires a global content and form.

This allows us to believe that not only in science there is a new global revolution, but with its help - a similar global revolution in education (Ursul, 2019 ${ }^{\circ}$ ). The emergence of complex global-revolutionary transformations in science and education is one of the main harbingers of the global sustainable world, which is focused on the transformation into the noosphere (Ursul \& Ursul, 2019 $)$. Science and education, which in this century can become a single globally advanced scientific and educational process, should change the trajectory of the social stage of evolution in the direction of its survival, preservation and further permanent sustainable progress.

\section{REFERENCES}

Ilyin, I., \& Ursul, A. (2016). Obrazovanie, obshchestvo, priroda: Evolyucionnyi podkhod $i$ global'nye perspektivy (Education, Society, Nature: Evolutionary Approach and Global Perspectives, in Russian). Moscow: Moscow University Publishing House.

Ursul, A. $\left(2018^{\mathrm{a}}\right)$. Vernadskii i global'nye issledovaniya (K 155-letiyu so dnya rozhdeniya uchyonogo) (V. I. Vernadsky and Global Studies (To the 155th Anniversary of the Scientist's Birth, in Russian). Age of globalisation, 3, 3-14. doi: 10.30884/vglob/2018.03.01.

Ursul, A. $\left(2018^{\mathrm{b}}\right)$. Stanovlenie nauki o global'nom mire (Formation of the Science of the Global World, in Russian). Sociodynamics, 10, 61-67. doi: 10.25136/ 
2409-7144.2018.10.27446.

Ursul, A. (2019ª). Novaya global'naya revolyuciya $v$ nauke (New Global Revolution in Science, in Russian). Issues of Filosophy, 8, 104-112.

Ursul, A. $\left(2019^{\mathrm{b}}\right)$. Global'nost' kak bazovoe ponyatie global'nykh issledovanij (Globality as a Basic Concept of Global Studies, in Russian). Philosophy and Culture, 6, 1-13. doi: 10.7256/2454-0757.
2019.6.29279.

Ursul, A. $\left(2019^{c}\right)$. Stanovlenie obrazovaniya global'nogo mira (Formation of Global World Education, in Russian). Age of Globalisation, 2, 121-134.

Ursul, A., \& Ursul, T. (2019 ${ }^{\mathrm{d}}$ ). Stanovlenie global'nogo mira. Puti i perspektivy (Formation of the Global World. Ways and Perspectives, in Russian). Saarbrücken: Palmarium Academic Publishing. 